\title{
Effect of dihydroferulic acid obtained from fermented rice bran extract on neuroprotection and behavioral recovery in an ischemic rat model
}

\author{
Sang Hyun $\mathrm{LEE}^{1}$, Dana $\mathrm{YEO}^{2}$, Jeong Hwa $\mathrm{HONG}^{1 *}$
}

\begin{abstract}
This study aimed to evaluate whether dihydroferulic acid ( $\mathrm{dFA}$ ) promoted the viability of $\mathrm{H}_{2} \mathrm{O}_{2}$-treated $\mathrm{PC} 12$ cells and functional recovery from ischemic injury. The animals were divided into four groups for the study: (1) the vehicle treated (saline, $1 \mathrm{~mL} / \mathrm{kg}$ ), (2) dFA $5 \mathrm{mg} / \mathrm{kg}$ treated, (3) dFA $10 \mathrm{mg} / \mathrm{kg}$ treated, and (4) dFA $20 \mathrm{mg} / \mathrm{kg}$ treated groups. Neurological deficit was evaluated using the modified neurological severity score. Real-time polymerase chain reaction analyses were performed with the protein disulphide isomerase (PDI), nuclear factor-E2-related factor 2 (Nrf2), nerve growth factor (NGF) and brain-derived neurotrophic factor (BDNF) genes. Immunohistochemical analysis was performed with the Iba-1 and MFG-E8 genes. dFA treatment improved the reduced viability of $\mathrm{PC} 12$ cells induced by $\mathrm{H}_{2} \mathrm{O}_{2}$ in a dose-dependent manner. Only $50 \mu \mathrm{M}$ of dFA significantly enhanced the transcription levels of antioxidant genes and neurotrophic factors compared to the vehicle group. In vivo dFA administration exerted a neuroprotective effect by reducing the infarct volume and enhancing behavioral function following cerebral ischemia. dFA treatment protected neuronal cells from ischemic injury and increased the transcription levels of anti-oxidant genes (PDI and Nrf2) and neurotrophic factors (BDNF and NGF). dFA treatment decreased the expression of Iba-1 and MFG-E8 genes, which signal neural cell death.
\end{abstract}

Keywords: fermented rice bran extract; dihydroferulic acid; anti-oxidant genes; ischemic brain injury; neuroprotective effect.

Practical Application: Dihydroferulic acid demonstrated a neuroprotective effect against ischemic brain injury and subsequently facilitated functional recovery.

\section{Introduction}

The incidence of ischemic stroke is reportedly high in several countries. It is one of the most common causes of death and disability. Ischemic stroke is caused by decreased oxygen supply to the brain cells, resulting in brain tissue damage (Yulug et al., 2006), cellular bioenergetic failure caused by cerebral hypoperfusion, followed by excitotoxicity, oxidative stress, blood-brain-barrier dysfunction, hemostatic activation, post-ischemic inflammation, and consequently, neuronal death. Stroke can cause certain sensory dysfunctions, language disorders, cognitive impairment, and loss of memory (Kruyt et al., 2008; Kam et al., 2012).

Few studies have focused on compounds obtained from foodstuff, owing to the increased focus on discovering physiologically functional foods in recent years (Verschuren, 2002). Among them, rice bran, which is used as animal feed, is mainly obtained by dehusking rice, contains several nutrients including protein, fat, lecithin, pyridoxine, vitamins A and B, oryzanol, and ferulic acid (FA) (Piotrowicz \& Salas-Mellado, 2017; Soi-Ampornkul et al., 2012). FA and dihydroferulic acid (dFA) are aromatic compounds, with known antioxidant effects (Rechner et al., 2001). Earlier studies have demonstrated several biological effects of FA including anti-inflammatory effects (Yu et al., 2006).

FA decreases infarct volume and apoptotic cell death after cerebral ischemic injury. It has cytoprotective effects against oxidative stress in neuronal cells (Sung et al., 2014). Antioxidants such as FA are expected to prevent lipid oxidation in food and prevent free-radical-induced diseases such as cancer, atherosclerosis, and aging, which are caused by oxidative tissue degeneration and brain injury after ischemia (Kikuzaki et al., 2002).

Nerve growth factor (NGF) and brain-derived neurotrophic factor (BDNF) play an important role in the development, differentiation, and survival of the neurons of the nervous system (Fantacci et al., 2013). Neurogenesis decreases after stroke and is a part of the aging process. Infarct size and the microglial and inflammatory response are likely to be affected in such patients (Moraga et al., 2015). Iba-1 is a novel calcium binding protein, which is specifically expressed in the activated microglia in the rat brain. This protein participates in regulating microglial function (Ito et al., 2001). Anti-inflammatory or anti-oxidant treatment may attenuate the increased microglial marker intensity in the infarcted brain (Kam et al., 2012).

This study aimed to determine whether dFA obtained from fermented rice bran extract promoted functional recovery from ischemic injury through the expression of genes that code for antioxidants, neurotrophic factors, ChAT, DCX, and SYP, and to evaluate the functional recovery from ischemia-induced cognitive impairment. 


\section{Materials and methods}

\subsection{Reagent}

RPMI 1640 cell culture medium, donor equine serum, fetal bovine serum (FBS), phosphate-buffered saline (PBS), trypsin solution, and penicillin were purchased from Hyclone Laboratories (Logan, UT, USA). HBSS, $\mathrm{N}_{2}$ supplement, and RPMI1640 phenol red free medium were obtained from Gibco BRL (Grand Island, NY, USA). PC12 cell lines were purchased from the Korean Cell Line Bank.

\subsection{Extraction of dFA from fermented rice bran}

The extraction process was performed according to the method described by Ingkasupart (2015). Fermentation and extraction of rice bran was performed as follows. For the starter culture, Lactobacillus plantarum Hong (KFCC 11556P) was cultured in MRS broth medium (Difco Laboratories, Detroit, MI, USA) at $37^{\circ} \mathrm{C}$ for $24 \mathrm{~h}$. Rice bran (100 g) was suspended in $900 \mathrm{~mL}$ distilled water, followed by autoclaving at $121{ }^{\circ} \mathrm{C}$ for $15 \mathrm{~min}$. The medium was cooled to room temperature, followed by the addition of $5 \%$ of the total volume of the starter culture and incubation at $37^{\circ} \mathrm{C}$ for $36 \mathrm{~h}$. The fermentation broth was autoclaved at $121^{\circ} \mathrm{C}$ for $15 \mathrm{~min}$ and centrifuged at $8,500 \times \mathrm{g}$ for $10 \mathrm{~min}$ to remove the cell mass. The supernatant was filtrated and a concentration of 54 brix was obtained by vacuum evaporation. dFA was separated from the fermented rice bran extract and subsequently purified using preparative-scale high performance liquid chromatography (Prep-HPLC). Prep-HPLC was performed by injecting $0.5 \mathrm{~mL}$ of filtered aqueous fermented rice bran extract, which was dissolved in methanol, onto an Agilent 1100 series Prep-HPLC system (Agilent Technologies, California, USA). Eluted fractions were subsequently extracted with ethyl acetate and injected to HPLC. The fraction containing the highest content of compound $\mathrm{X}$ was selected for liquid chromatography-mass spectrometry (LC/MS) analysis.

\subsection{Cell culture and treatment}

PC12 cells were cultured in RPMI-1640 media (1X) with $2.05 \mathrm{mM}$ L-glutamine (HyClone ${ }^{\mathrm{mm}}$, \#SH30027.01, USA) with $10 \%$ heat inactivated horse serum, $5 \%$ FBS, 100 units $/ \mathrm{mL}$ of penicillin, and 100 units $/ \mathrm{mL}$ of streptomycin at $37^{\circ} \mathrm{C}$ in $95 \%$ air and $5 \% \mathrm{CO}_{2}$-humidified atmosphere. The cells were subcultured once or twice a week in trypsin-EDTA, $0.25 \% 1 \mathrm{X}$ solution (Hyclone, \#SH30042.01) in 12-well plates $\left(1 \times 10^{5}\right.$ cells $\left./ \mathrm{mL}\right)$, usually after 1 day of incubation in a $\mathrm{CO}_{2}$ incubator at $37^{\circ} \mathrm{C}$. A vehicle (saline treatment) and different concentrations of dFA $(6.25,12.5,25,50 \mu \mathrm{M}$ in culture media) were used to study the effects of dFA experimentally for $24 \mathrm{~h}$.

\subsection{Evaluation of cell viability}

Experiments were conducted $24 \mathrm{~h}$ after treating the cells with drugs. The cells were treated with $\mathrm{H}_{2} \mathrm{O}_{2}(0.5 \mathrm{mM})$ for $30 \mathrm{~min}$. The cells were harvested gently and stained with $0.4 \%$ trypan blue solution (Sigma-Aldrich, \#T8154, USA) mixed with the same quantity of serum free culture media for 5 min after $\mathrm{H}_{2} \mathrm{O}_{2}$ treatment. Viability was calculated as the percentage ratio of the live cell number to the number of total cells using National Institutes of Health (NIH) Image software (Image J).

\subsection{Animals}

Male Sprague-Dawley rats weighing 240-290 g at the time of surgery were used for the study. The animals were housed in pairs in cages in a temperature-controlled room $\left(22 \pm 3{ }^{\circ} \mathrm{C}\right)$ under a light-dark cycle (12-h/12-h). They had free access to food and water, except during the day before surgery. This study was conducted in accordance with the Guidelines for INJE University, with approval from the Institutional Animal Care and Use Committee (No. 55) for the use of animals in research.

\subsection{Experimental design for drug treatments}

The animals were divided to 2 experiments. Experiment 1 included screening the effect of dFA obtained from rice bran on infarct volume and behavior. Experiment 2 investigated the neuroprotective effects of dFA obtained from rice bran on anti-apoptosis, gene expression, and expression of MFG-E8 and Iba-1. dFA was dissolved in saline and injected intraperitoneally. The four groups studied included: (1) the vehicle group (saline, $1 \mathrm{~mL} / \mathrm{kg})(\mathrm{n}=5),(2)$ the dFA 5 group (dFA injection only, $5 \mathrm{mg} / \mathrm{kg}$ ) $(\mathrm{n}=5),(3)$ the dFA 10 group (dFA injection only, $10 \mathrm{mg} / \mathrm{kg})(\mathrm{n}=5)$, and (4) the dFA 20 group (dFA injection only, $20 \mathrm{mg} / \mathrm{kg}$ ) $(n=5)$. The rats were treated with saline and dFA, once a day during 3 days after middle cerebral artery occlusion (MCAO).

\subsection{Induction of focal cerebral ischemia}

MCAO was achieved according to the methods described previously, with modifications (Longa et al., 1989). The right common carotid artery was exposed briefly, and the right external and internal carotid arteries were isolated. The external carotid artery was ligated at the distal end, which was cut off. A 4-0 nylon thread pre-coated with silicon was inserted from the right external to the right internal carotid artery, to occlude the origin of the right middle cerebral artery. Subsequently, it was directed distally and upwards, through the right internal carotid artery to a distance of approximately $20 \mathrm{~mm}$ from the carotid bifurcation, to occlude the origin of the middle cerebral artery. After $1 \mathrm{~h}$, the thread was withdrawn for reperfusion. All the animals experienced ischemia for $1 \mathrm{~h}$, followed by reperfusion. Rectal temperature was maintained at $37 \pm 0.5^{\circ} \mathrm{C}$ throughout the surgical procedure. The brains were dissected into $2-\mathrm{mm}$ coronal sections in a metallic brain matrix, immersed sequentially in a $2 \%$ solution of 2,3,5-triphenyltetrazolium chloride (TTC), and in normal saline at $37^{\circ} \mathrm{C}$ for $10 \mathrm{~min}$, and subsequently, fixed in $10 \%$ formalin for $10 \mathrm{~s}$. The infarct area in the brain section was measured using the NIH Image software (Image J). The ischemic lesion volume was calculated as the sum of the ischemic lesions obtained from five brain slices from half the hemisphere.

\subsection{Neurological deficit scores}

All rats were evaluated using the modified neurological severity score (mNSS) (Chen et al., 2001). The mNSS is a composite of motor (muscle status and abnormal movement), sensory 
(visual, tactile, and proprioceptive), reflex, and balance tests. Neurological function was graded on a scale of 0 to 18 (normal score, 0 ; maximal deficit score, 18). The test was conducted by an investigator who was blinded to the experimental groups.

\subsection{RT-PCR analysis}

The side with the lesions from each group was harvested for real-time polymerase chain reaction (RT-PCR) analysis. Total RNA was extracted using the acid guanidinium isothiocyanate-phenol-chloroform method with the TRI Reagent, followed by extraction and precipitation with isopropyl alcohol. cDNA was synthesized from equal amounts of total RNA using superscript III reverse transcriptase, and PCR was performed with high fidelity Taq DNA polymerase. The expression level of the gene of interest was corrected for that of the housekeeping gene, $\beta$-actin. PCR products of different genes were detected using electrophoresis with 1.5\% agarose gel containing ethidium bromide. Band intensities were quantified using the NIH software (Image J) and normalized with $\beta$-actin.

\subsection{Immunohistochemistry}

The rats were sacrificed 3 days after MCAO and fixed by cardiac perfusion with $4 \%$ paraformaldehyde in a $0.1 \mathrm{M}$ PBS. The samples were embedded in an embedding medium (O. C. T. compound, Sakura Finetek USA, Inc.) for frozen tissue specimens and frozen. The brains were sliced into coronal sections $(10 \mu \mathrm{m})$ using a cryostat (HM 525, Thermo Scientific, USA). The sections were incubated with primary antibodies for $24 \mathrm{~h}$ at $4{ }^{\circ} \mathrm{C}$ after blocking with normal serum for $2 \mathrm{~h}$ at room temperature. Anti-NeuN (1:700, Chemicon, USA), anti- $\beta$-Tubulin III (1:700, Sigma, USA), anti-SYP (1:500, Millipore, USA), ChAT (1:100, Millipore, USA), and anti-DCX (1:1000, Abcam, England) antibodies diluted in tris-buffered saline (TBS) containing 1\% bovine serum albumin $(\mathrm{w} / \mathrm{v})$ and $0.3 \%$ Triton-X 100 were used for immunohistochemical analysis in this study. The sections were incubated with secondary antibody-conjugated fluorescein isothiocyanate (1:300, Sigma, USA) for $2 \mathrm{~h}$, at room temperature, after rinsing with TBS. Subsequently, the sections were rinsed with TBS again and mounted in an aqueous mounting medium. The resulting immunoreactivity was visualized using fluorescence microscopy (Carl Zeiss Axioskop2+, Germany).

\subsection{Statistical analysis}

All data were expressed as mean \pm SD and were representative of the results obtained from three independent experiments. Statistical comparisons of differences among the groups were performed using Student's t-test. ${ }^{*} \mathrm{p}<0.05$, and ${ }^{* *} \mathrm{p}<0.01$ were considered statistically significant.

\section{Results}

\subsection{Gene expressions in PC12 cells treated with dFA}

The reduction in viability induced by $\mathrm{H}_{2} \mathrm{O}_{2}$ exposure was improved by dFA treatment in a dose-dependent manner. A concentration of $50 \mu \mathrm{M}$ of dFA prevented approximatively $19-23 \%$ of cell death induced by $\mathrm{H}_{2} \mathrm{O}_{2}$ (data not shown). RT-PCR was used to analyze the effects of dFA on the anti-oxidant genes (Nrf2 and PDI), which encode antioxidant proteins, endogenous neurotrophic factors, and the BDNF and NGF genes. The harvested cells were subjected to RT-PCR analysis, $24 \mathrm{~h}$ after drug treatment.

The expression levels of the Nrf2 and PDI genes were significantly increased in the dFA treatment groups. The expression levels in the $50 \mu \mathrm{M}$-dFA group were significantly elevated when compared with those in the vehicle group (Figure 1A). The expression levels of the BDNF and NGF genes were significantly elevated in the
(A)
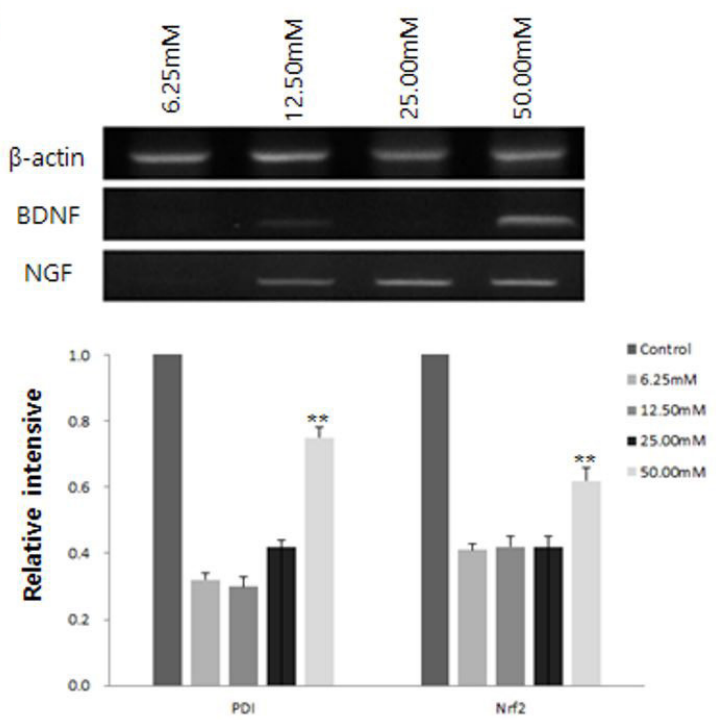

(B)
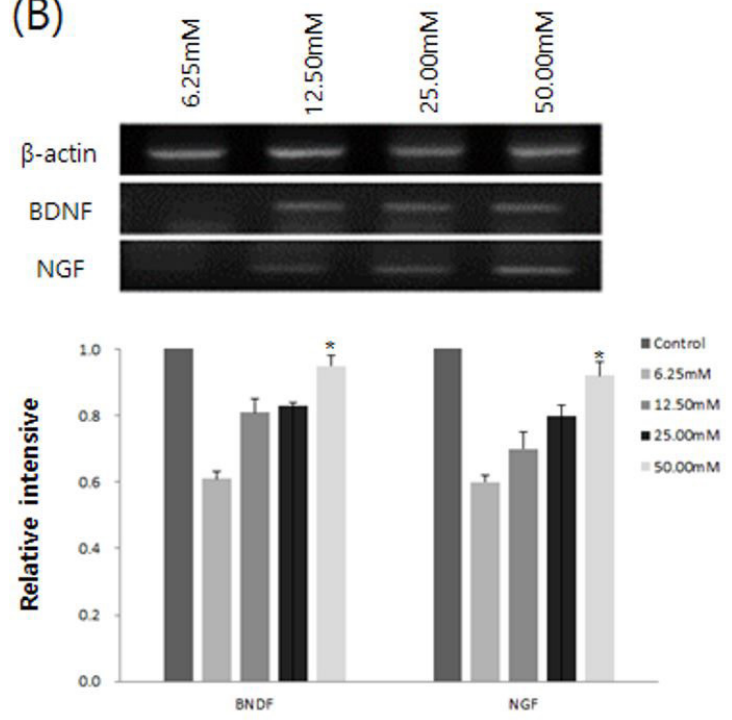

Figure 1. Effects of serial concentration of dFA on the gene expressions of PDI, Nrf2, BDNF, and NGF in PC12 cells (A, B) Specific gene expressions were determined in relation to the expression of $\beta$-actin using RT-PCR. Experiments were repeated three times and individual values are expressed as the mean \pm S.E.M. ${ }^{\star} \mathrm{p}<0.05,{ }^{\star *} \mathrm{p}<0.01$ versus individual vehicle group. dFA: dihydroferulic acid; RT-PCR: real-time polymerase chain reaction; PDI: protein disulphide isomerase; Nrf2: nuclear factor-E2-related factor 2; BDNF: brain-derived neurotrophic factor; NGF: nerve growth factor; S.E.M: standard error of the mean. 
dFA treated groups. Moreover, only $50 \mu \mathrm{M}$ of dFA significantly elevated the expression levels when compared to the vehicle group $\left({ }^{\star} \mathrm{p}<0.05\right.$ and ${ }^{\star *} \mathrm{p}<0.01$; Figure $\left.1 \mathrm{~B}\right)$.

\subsection{Infarct volume and functional recovery 3 days after middle cerebral artery occlusion}

The borders of the TTC stain enclosing the white infarct area were readily distinguishable, in contrast to the red color of the normal area (Kam et al., 2012). The infarct volumes of the rats in the vehicle-treated group were significantly larger than those of the rats treated with dFA $(20 \mathrm{mg} / \mathrm{kg})$. Quantitative measurement of the infarct volume was performed in the section $4.00 \mathrm{~mm}$ to $-6.00 \mathrm{~mm}$ away from the bregma, according to the rat brain atlas (Paxinos \& Watson, 2006). The infarct volumes of the vehicle-treated group and the groups treated with $5 \mathrm{mg} / \mathrm{kg}, 10 \mathrm{mg} / \mathrm{kg}$, and $20 \mathrm{mg} / \mathrm{kg}$ of dFA were $48.31 \pm 4.41$, $44.13 \pm 2.05,39.09 \pm 0.7$, and $22.56 \pm 3.47 \%$, respectively, of the total area of the brain section. Only treatment with dFA $20 \mathrm{mg} / \mathrm{kg}$ reduced the infarct size, compared with the vehicle group $\left({ }^{*} \mathrm{p}<0.05\right.$ and $\left.{ }^{* *} \mathrm{p}<0.01\right)$ (Figure $\left.2 \mathrm{~A}, \mathrm{~B}\right)$.

We examined the effect of dFA treatment on the reduction in functional deficits induced by ischemic injury. The mNSS test showed that motor and sensory functions were impaired due to ischemic insult (Baek et al., 2014). All the groups showed no significant enhancement 1 day after ischemic brain injury.
However, there was significant functional recovery in the dFA treated groups $(10$ and $20 \mathrm{mg} / \mathrm{kg}$ ) 3 days after treatment, compared to that in the vehicle group (Figure 2C).

\subsection{Effect of dFA on the expression of genes encoding antioxidants and neurotrophic factors}

RT-PCR was used to analyze the effects of dFA on the anti-oxidant genes (PDI and Nrf2) expression encoding antioxidant proteins and endogenous neurotrophic factors encoded by the BDNF and NGF genes. The area in the ipsilateral whole brain with the lesions was subjected to RT-PCR analysis 3 days after focal cerebral ischemia. The expression levels of Nrf2, BDNF, and NGF genes were significantly elevated in the dFA $20 \mathrm{mg} / \mathrm{kg}$ group, when compared to the vehicle-treated group (Figure 3A, B).

\subsection{Immunoreactivity in the infarct area}

Immunohistochemical analysis was performed 3 days after inducing MCAO. The presence of astrocyte markers MFG-E8 and microglial markers Iba-1 in the infarct area of the vehicle and dFA-treated groups was determined. Immunohistochemical analysis showed that the intensity of the MFG-E8 and Iba-1 signals for microglia and astrocytes was higher in the in vehicle group and MFG-E8 and Iba-1 expression was considerably lower in the dFA-treated group than that in the vehicle group (Figure 4A, B).
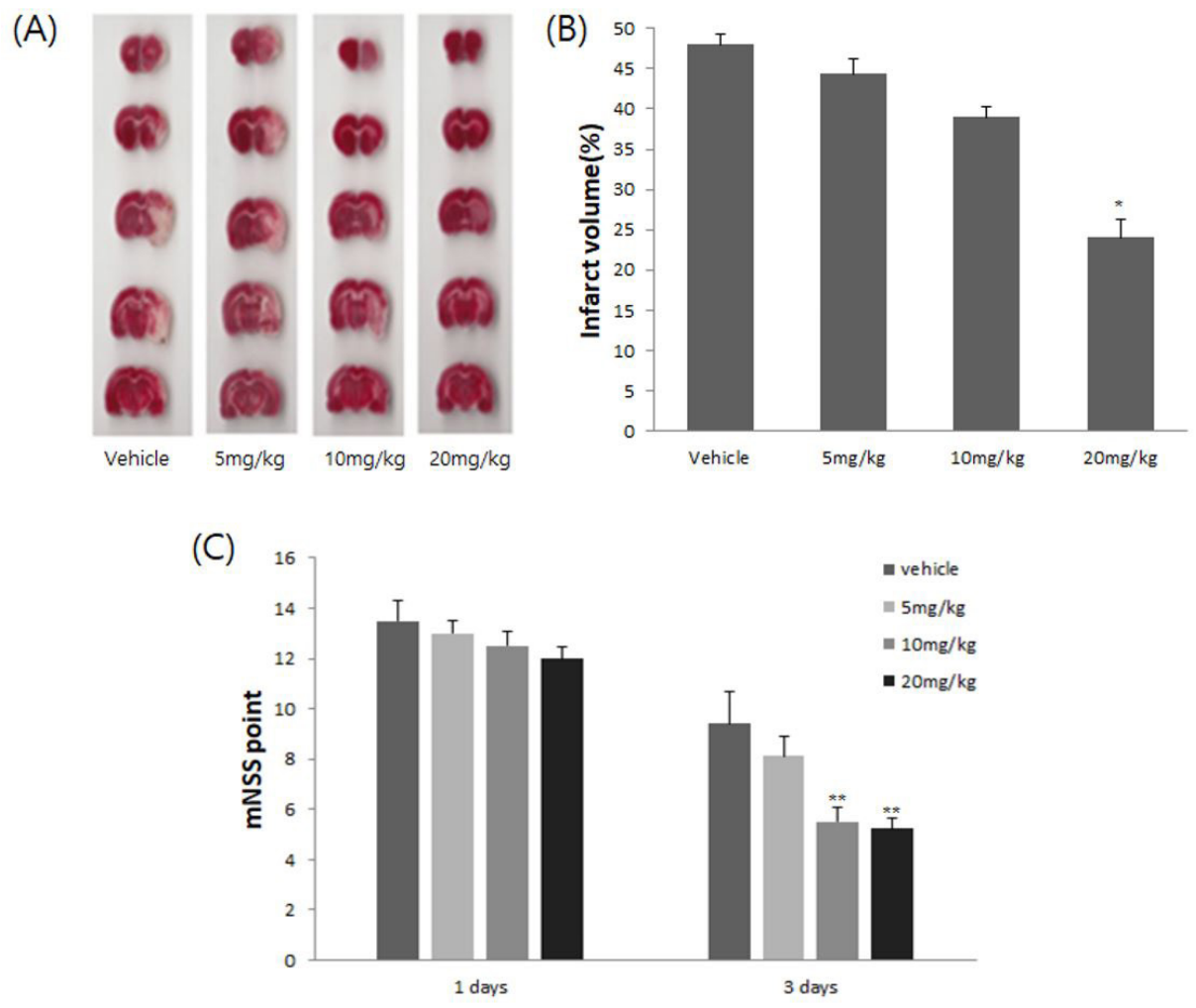

Figure 2. Effect of dFA on the infarct volume and functional behavioral recovery 3 days after MCAO (A) TTC-stained coronal sections from vehicle, dFA $5 \mathrm{mg} / \mathrm{kg}, 10 \mathrm{mg} / \mathrm{kg}$ and $20 \mathrm{mg} / \mathrm{kg}$ groups (B) The infarct volume was calculated as the infarct area's X thickness (2 mm) and expressed as a percentage of the lesion half of the brain $(\mathrm{C})$ Neurological functional tests were performed 1 and 3 days after MCAO Data are shown as standard error of the mean $(n=5){ }^{*} \mathrm{p}<0.05,{ }^{* *} \mathrm{p}<0.01$ versus individual vehicle group. MCAO: middle cerebral artery occlusion; dFA: dihydroferulic acid; TTC: 2,3,5-triphenyltetrazolium chloride. 
(A)
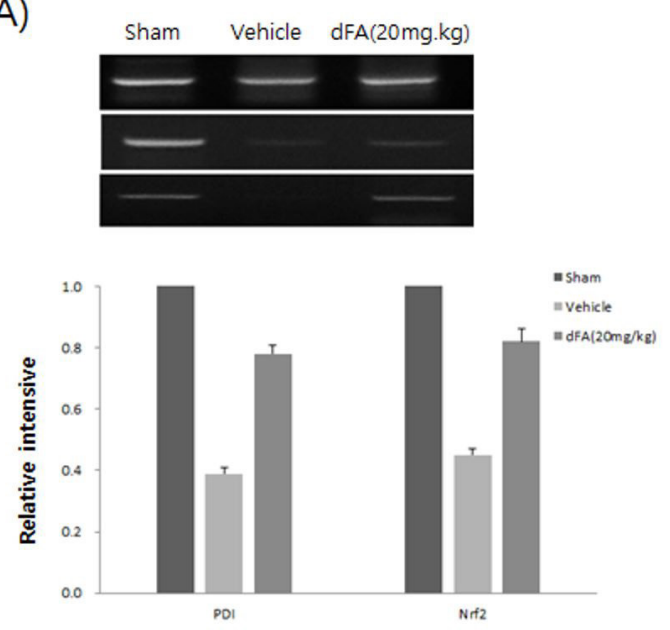

(B)
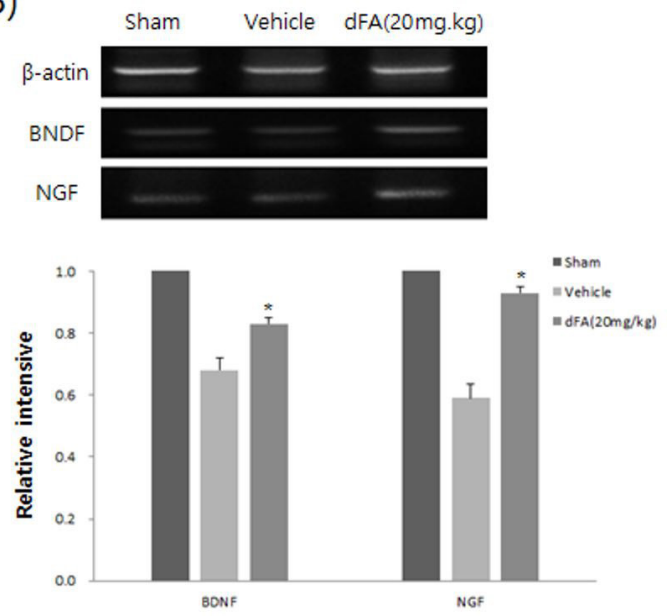

Figure 3. Effect of dFA on the gene expressions of PDI, Nrf2, BDNF, and NGF in the ipsilateral whole brain of the lesioned area. (A, B) Specific gene expressions were determined in relation to the expression of $\beta$-actin using RT-PCR. Experiments were repeated three times and individual values are expressed as the mean \pm S.E.M. ${ }^{*} \mathrm{p}<0.05,{ }^{* *} \mathrm{p}<0.01$ versus individual vehicle group; dFA: dihydroferulic acid; RT-PCR: real-time polymerase chain reaction; PDI: protein disulphide isomerase; Nrf2: nuclear factor-E2-related factor 2; BDNF: brain-derived neurotrophic factor; NGF: nerve growth factor; S.E.M: standard error of the mean.

(A)

Iba-1

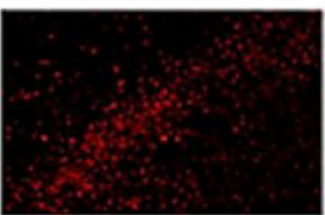

$\mathrm{dFA}(20 \mathrm{mg} / \mathrm{kg})$

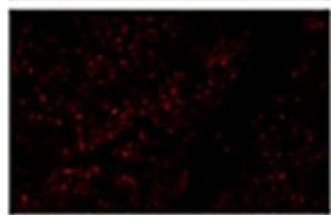

(B)

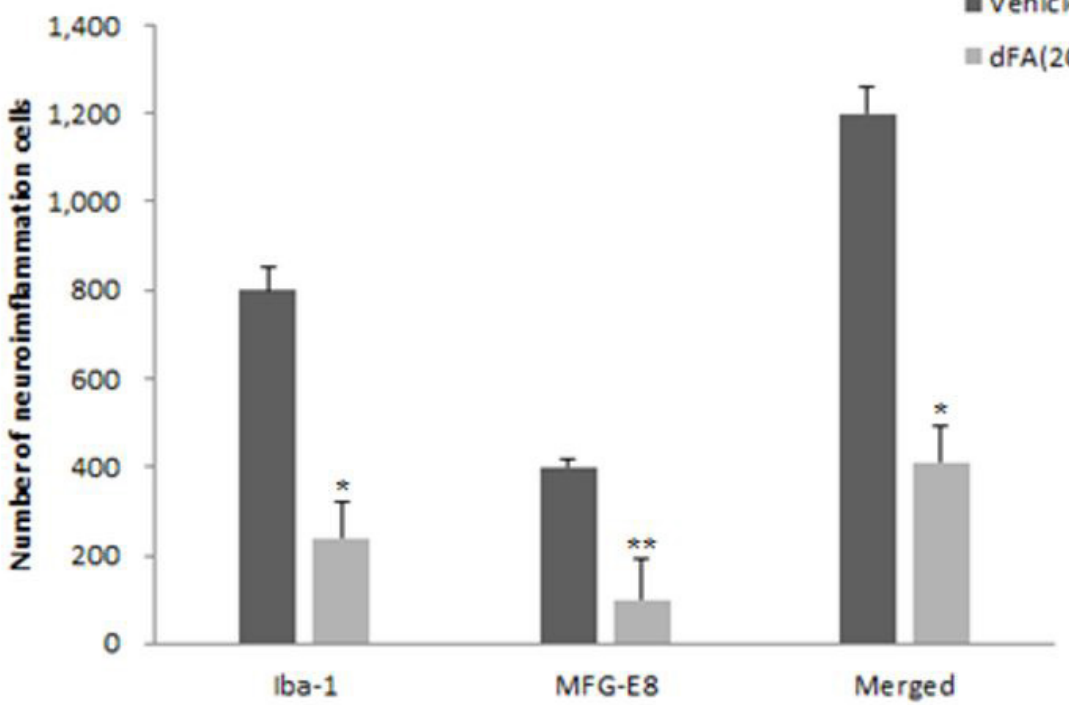

MFG-E8
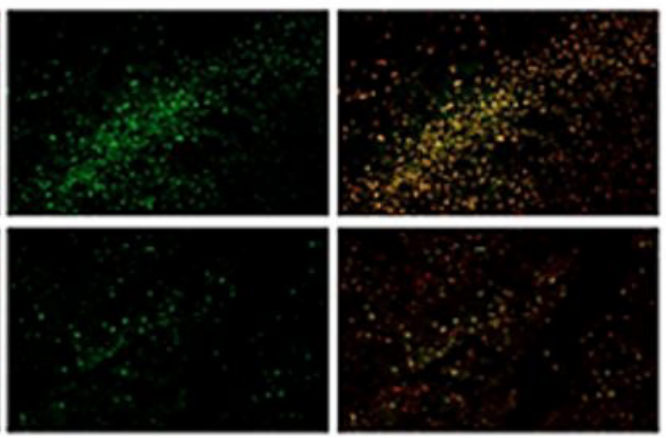

vehicle

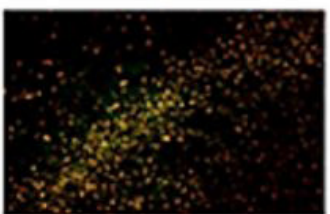

dFA $(20 \mathrm{mg} / \mathrm{kg})$ 


\section{Discussion}

Rice is an essential food and dietary ration worldwide, especially in Asian countries. It contains fiber and many types of antioxidants, such as phytic acid, FA, and oryzanols (Soi-Ampornkul et al., 2012). Rice bran extract might be a potential nutraceutical for the prevention of oxidative stress in neurodegenerative diseases (Hagl et al., 2013; Baek et al., 2014).

Earlier studies reported that FA is one of the most abundant phenolic anti-oxidants found in fruits, vegetables, coffee, and rice (Gohil et al., 2012), which induced functional recovery in the ischemic brain, as shown by our study (Baek et al., 2014). It can be metabolized into other phenolic compounds with lower molecular weights, such as vaillic acid and dFA (Zhao et al., 2004). We analyzed the treatment effect of dFA. The survival rates of PC12 cells in the dFA treatment group increased significantly after treatment with dFA. We used HPLC to demonstrate that dFA was a major component of fermented rice bran extract (data not shown). Rice bran fermentation produced the highest concentration of dFA, which was $55.0 \mathrm{mg}$ of $\mathrm{dFA} / \mathrm{L}$ culture broth. Thus, we treated PC12 cells with fermented rice bran extract, with a molecular weight equal to the compound obtained from rice bran fermentation using PREP-HPLC and was close to the standard dFA concentration: $196.20 \mathrm{~g} / \mathrm{mole}$ (Ingkasupart, 2015). dFA treatment showed the highest antioxidant effect. Subsequently, the cells were treated with various concentrations of $\mathrm{dFA}$, and the survival rate was measured. The proportion of living cells increased, relative to increase in concentration from 6.25 to $50 \mu \mathrm{M}$. Thus, dFA may have an anti-oxidant effect. We used RT-PCR analysis to quantify the expression of the antioxidant-related genes PDI and Nrf2. PDI is an oxidoreductase enzyme that catalyzes the formation and isomerization of protein disulfide bonds (Frand A. R. et al., 2000). The up-regulation of PDI expression was observed in the PC12 cells and the animal forebrain after transient ischemia.

Moreover, the overexpression of this gene improves the loss of cell viability induced by hypoxia (Tanaka et al., 2000). Nrf2 is an important transcriptional factor regulating several phase II detoxifying and antioxidant enzymes. Thus, the early expression of Nrf2 may represent an important neuroprotective antioxidant mechanism (Wasserman \& Fahl, 1997). The dFA elevated the expression of the anti-oxidant genes, PDI and Nrf2, and also enhanced the expression of the BDNF and NGF genes, which code for endogenous neurotrophic factors.

We also studied the treatment effect of dFA on the rat ischemic brain. Administration of $20 \mathrm{mg} / \mathrm{kg}$ of dFA markedly reduced the infarct size in the ischemic brains of rats. Treatment with dFA $(20 \mathrm{mg} / \mathrm{kg})$ also enhanced the functional behavioral recovery of the ischemic brain in rats. The functional recovery effect of dFA may be associated with the increased expression of anti-oxidants genes and neurotrophic factor genes. Neurotrophic factors are essential for neuronal survival and differentiation, as well as for the maintenance of neuronal functions (Snider, 1994).

Neuroinflammation is implicated in secondary injury (Danton \& Dietrich, 2003) and might lead to more severe and persistent behavioral deficits and impaired recovery after stroke (Moraga et al., 2015). The injury activates neuroinflammatory cells such as microglia and astrocytes. In this study, treatment with dFA $(20 \mathrm{mg} / \mathrm{kg})$ showed a substantial reduction in immunostaining for neuroinflammatory cells in the infarct area. Our findings suggest that dFA might reduce the expressions of MFG-E8 and Iba-1 genes, which are neuroinflammatory cellular markers in the ischemic brain.

Therefore, these results suggested that dFA obtained from fermented rice bran (a natural therapeutic source) may have a neuroprotective effect and facilitate functional recovery in the ischemic brain of rats. However, it is necessary to identify the molecular mechanisms underlying the neuroprotective efficacy of dFA. Moreover, further studies are needed to investigate the bioavailability of dFA for its clinical application, and to provide scientific evidence of the effect of dFA treatment in promoting functional recovery after ischemic brain injury.

\section{Conclusions}

In conclusion, our results demonstrate that $\mathrm{dFA}$, the main compound of fermented rice bran, may improve functional recovery and provide neuroprotection against ischemic injury, through the upregulation of genes coding for antioxidants and neurotrophic factors. dFA treatment provided neuroprotection by suppressing the expressions of Iba-1 and MFG-E8 genes, which signal cell death.

\section{Acknowledgements}

This research was supported by High Value-added Food Technology Development Program [112074-3], Ministry of Agriculture, Food and Rural Affairs.

\section{Reference}

Baek, S. E., Kim, J. Y., Song, W. T., Lee, S. H., Hong, J. H., Lee, C. K., \& Kang, S. K. (2014). Neuroprotective effect of rice bran extract supplemented with ferulic acid in the rat model of ischemic brain injury. Animal Cells and Systems, 18(2), 93-100. http://dx.doi.org/ 10.1080/19768354.2014.904249.

Chen, J., Sanberg, P. R., Li, Y., Wang, L., Lu, M., Willing, A. E., SanchezRamos, J., \& Chopp, M. (2001). Intravenous administration of human umbilical cord blood reduces behavioral deficits after stroke in rats. Stroke, 32(11), 2682-2688. http://dx.doi.org/10.1161/hs1101.098367. PMid:11692034.

Danton, G. H., \& Dietrich, W. D. (2003). Inflammatory mechanisms after ischemia and stroke. Journal of Neuropathology and Experimental Neurology, 62(2), 127-136. http://dx.doi.org/10.1093/jnen/62.2.127. PMid:12578222.

Fantacci, C., Capozzi, D., Ferrara, P., \& Chiaretti, A. (2013). Neuroprotective role of nerve growth factor in hypoxic-ischemic brain injury. Brain Sciences, 3(3), 1013-1022. http://dx.doi.org/10.3390/brainsci3031013. PMid:24961518.

Gohil, K. J., Kshirsagar, S. B., \& Sahane, R. S. (2012). Ferulic acid:a comprehensive pharmacology of an important bioflavonoid. International Journal of Pharmaceutical Sciences and Research, 8, 700-710.

Hagl, S., Kocher, A., Schiborr, C., Eckert, S. H., Ciobanu, I., Birringer, M., El-Askary, H., Helal, A., Khayyal, M. T., Frank, J., Muller, W. E., \& Eckert, G. P. (2013). Rice bran extract protects from mitochondrial 
dysfunction in guinea pig brains. Pharmacological Research, 76, 17 27. http://dx.doi.org/10.1016/j.phrs.2013.06.008. PMid:23827162.

Ingkasupart, P. (2015). Enhanced production of neuroprotective compounds from rice bran fermentation using lactobacillus plantarum KFCC $11556 P$ (Ph.D dissertation). Inje University, Gimhae, Gyeongnam, Korea.

Ito, D., Tanaka, K., Suzuki, S., Dembo, T., \& Fukuuchi, Y. (2001). Enhanced expression of Iba1, ionized calcium-binding adapter molecule 1 , after transient focal cerebral ischemia in rat brain. Stroke, 32(5), 12081215. http://dx.doi.org/10.1161/01.STR.32.5.1208. PMid:11340235.

Kam, K. Y., Jalin, A. M. A., Choi, Y. W., Kaengkan, P., Park, S. W., Kim, Y. H., \& Kang, S. G. (2012). Ziprasidone attenuates brain injury after focal cerebral ischemia induced by middle cerebral artery occlusion in rats. Progress in Neuro-Psychopharmacology \& Biological Psychiatry, 39(1), 69-74. http://dx.doi.org/10.1016/j. pnpbp.2012.05.010. PMid:22627197.

Kikuzaki, H., Hisamoto, M., Hirose, K., Akiyama, K., \& Taniguchi, H. (2002). Antioxidant properties of ferulic acid and its related compounds. Journal of Agricultural and Food Chemistry, 50(7), 2161-2168. http://dx.doi.org/10.1021/jf011348w. PMid:11902973.

Kruyt, N. D., Nys, G. M., van der Worp, H. B., van Zandvoort, M. J., Kappelle, L. J., \& Biessels, G. J. (2008). Hyperglycemia and cognitive outcome after ischemic stroke. Journal of the Neurological Sciences, 270(1-2), 141-147. http://dx.doi.org/10.1016/j.jns.2008.02.020. PMid:18387635.

Longa, E. Z., Weinstein, P. R., Carlson, S., \& Cummins, R. (1989). Reversible middle cerebral artery occlusion without craniectomy in rats. Stroke, 20(1), 84-91. http://dx.doi.org/10.1161/01.STR.20.1.84. PMid:2643202.

Moraga, A., Pradillo, J. M., García-Culebras, A., Palma-Tortosa, S., Ballesteros, I., Hernández-Jiménez, M., Moro, M. A., \& Lizasoain, I. (2015). Aging increases microglial proliferation, delays cell migration, and decreases cortical neurogenesis after focal cerebral ischemia. Journal of Neuroinflammation, 12(1), 87. http://dx.doi.org/10.1186/ s12974-015-0314-8. PMid:25958332.

Paxinos, G., \& Watson, C. (2006). The rat brain in stereotaxic coordinates. London: Academic Press.

Piotrowicz, I. B. B., \& Salas-Mellado, M. M. (2017). Protein concentrates from defatted rice bran: preparation and characterization. Food Science and Technology, 37(Suppl. 1), 165-172. http://dx.doi. org/10.1590/1678-457x.34816.
Rechner, A. R., Spencer, J. P. E., Kuhnle, G., Hahn, U., \& Rice-Evans, C. A. (2001). Novel biomarkers of the metabolism of caffeic acid derivatives in vivo. Free Radical Biology \& Medicine, 30(11), 1213-1222. http://dx.doi.org/10.1016/S0891-5849(01)00506-8. PMid:11368919.

Snider, W. D. (1994). Funcions of the neurotrophins during nervous system development: what the knockouts are teaching us. Cell, 77(5), 627-638. http://dx.doi.org/10.1016/0092-8674(94)90048-5. PMid:8205613.

Soi-Ampornkul, R., Junnu, S., Kanyok, S., Liammongkolkul, S., Katanyoo, W., \& Umpornsirirat, S. (2012). Antioxidative and neuroprotective activities of the pre-germinated brown rice extract. Food and Nutrition Sciences, 3(1), 135-140. http://dx.doi.org/10.4236/fns.2012.31020.

Sung, J. H., Gim, S. A., \& Koh, P. O. (2014). Ferulic acid attenuates the cerebral ischemic injury-induced decrease in peroxiredoxin-2 and thioredoxin expression. Neuroscience Letters, 566, 88-92. http:// dx.doi.org/10.1016/j.neulet.2014.02.040. PMid:24582902.

Tanaka, S., Uehara, T., \& Nomura, Y. (2000). Up-regulation of proteindisulfide isomerase in response to hypoxia/brain ischemia and its protective effect against apoptotic cell death. The Journal of Biological Chemistry, 275(14), 10388-10393. http://dx.doi.org/10.1074/ jbc.275.14.10388. PMid:10744727.

Verschuren, P. M. (2002). Functional Foods: Scientific and Global Perspectives. British Journal of Nutrition, 88(S2), S126-S130. http:// dx.doi.org/10.1079/BJN2002675.

Wasserman, W. W., \& Fahl, W. E. (1997). Functional antioxidant responsive elements. Medical Science, 94(10), 5361-5366. PMid:9144242.

Yu, L., Zhang, Y., Ma, R., Bao, L., Fang, J., \& Yu, T. (2006). Potent protection of ferulic acid against excitotoxic effects of maternal intragastric administration of monosodium glutamate at a late stage of pregnancy on developing mouse fetal brain. European Neuropsychopharmacology, 16(3), 170-177. http://dx.doi.org/10.1016/j. euroneuro.2005.08.006. PMid:16257184.

Yulug, B., Yildiz, A., Hudaoglu, O., Kilic, E., Cam, E., \& Schäbitz, W. R. (2006). Olanzapine attenuates brain damage after focal cerebral ischemia in vivo. Brain Research Bulletin, 71(1-3), 296-300. http:// dx.doi.org/10.1016/j.brainresbull.2006.09.018. PMid:17113959.

Zhao, Z., Egashira, Y., \& Sanada, H. (2004). Ferulic acid quickly absorbed from rat stomach as the free form and then conjugated mainly in liver. The Journal of Nutrition, 134(11), 3083-3088. http://dx.doi. org/10.1093/jn/134.11.3083. PMid:15514279. 